\title{
Concurrent validity and reliability of the Alberta Infant Motor Scale in premature infants
}

\author{
Kênnea Martins Almeida, ${ }^{1}$ Maria Virginia Peixoto Dutra, ${ }^{2}$ Rosane Reis de Mello, ${ }^{3}$ \\ Ana Beatriz Rodrigues Reis, ${ }^{4}$ Priscila Silveira Martins ${ }^{5}$
}

\begin{abstract}
Objective: To verify the concurrent validity and interobserver reliability of the Alberta Infant Motor Scale (AIMS) in premature infants followed-up at the outpatient clinic of Instituto Fernandes Figueira, Fundação Oswaldo Cruz (IFF/ Fiocruz), in Rio de Janeiro, Brazil.
\end{abstract}

Methods: A total of 88 premature infants were enrolled at the follow-up clinic at IFF/Fiocruz, between February and December of 2006. For the concurrent validity study, 46 infants were assessed at either $6(n=26)$ or $12(n=20)$ months' corrected age using the AIMS and the second edition of the Bayley Scales of Infant Development, by two different observers, and applying Pearson's correlation coefficient to analyze the results. For the reliability study, 42 infants between 0 and 18 months were assessed using the Alberta Infant Motor Scale, by two different observers and the results analyzed using the intraclass correlation coefficient.

Results: The concurrent validity study found a high level of correlation between the two scales $(r=0.95)$ and one that was statistically significant $(p<0.01)$ for the entire population of infants, with higher values at 12 months $(r=$ $0.89)$ than at 6 months $(r=0.74)$. The interobserver reliability study found satisfactory intraclass correlation coefficients at all ages tested, varying from 0.76 to 0.99 .

Conclusions: The AIMS is a valid and reliable instrument for the evaluation of motor development in high-risk infants within the Brazilian public health system.

J Pediatr (Rio J). 2008;84(5):442-448: Prematurity, child development, assessment, Alberta Infant Motor Scale, validity and reliability.

\section{Introduction}

Over the last 3 decades there has been a significant increase in the survival rate of infants born prematurely, both globally and in Brazil. ${ }^{1,2}$ A large number of scientific and technological advances in obstetric and neonatal care have contributed to this. ${ }^{3-6}$

1. Mestre, Instituto Fernandes Figueira, Fundação Oswaldo Cruz (Fiocruz), Rio de Janeiro, RJ, Brazil. Professora substituta, Universidade Federal de Juiz de Fora, Juiz de Fora, MG, Brazil. Fisioterapeuta, Hospital dos Servidores do Estado, Rio de Janeiro, RJ, Brazil.

2. Doutora, Instituto Alberto Luiz Coimbra de Pós-Graduação e Pesquisa de Engenharia (COPPE), Universidade Federal do Rio de Janeiro (UFRJ), Rio de Janeiro, RJ, Brazil. Médica pesquisadora. Professora, Pós-Graduação em Saúde da Criança e da Mulher, Instituto Fernandes Figueira, Fiocruz, Rio de Janeiro, RJ, Brazil.

3. Doutora, Instituto Fernandes Figueira, Fiocruz, Rio de Janeiro, RJ, Brazil. Médica pesquisadora. Professora, Pós-Graduação em Saúde da Criança e da Mulher, Instituto Fernandes Figueira, Fiocruz, Rio de Janeiro, RJ, Brazil.

4. Psicóloga clínica. Mestranda, Pós-Graduação em Saúde da Criança e da Mulher, Instituto Fernandes Figueira, Fiocruz, Rio de Janeiro, RJ, Brazil.

5. Neurologista infantil. Fisiatra. Mestranda, Pós-Graduação em Saúde da Criança e da Mulher, Instituto Fernandes Figueira, Fiocruz, Rio de Janeiro, RJ, Brazil. Financial support: Coordenação de Aperfeiçoamento de Pessoal de Nível Superior (CAPES); bursary student: Kênnea Martins Almeida.

Support: Programa Estratégico de Apoio à Pesquisa em Saúde, 4th edition (PAPES IV); Instituto Fernandes Figueira, Fiocruz; Conselho Nacional de Desenvolvimento Científico e Tecnológico (CNPq).

No conflicts of interest declared concerning the publication of this article.

Suggested citation: Almeida KM, Dutra MV, de Mello RR, Reis AB, Martins PS. Concurrent validity and reliability of the Alberta Infant Motor Scale in premature infants. J Pediatr (Rio J). 2008;84(5):442-448.

Manuscript received Mar 31 2008, accepted for publication Aug 112008.

doi:10.2223/JPED.1836 
Infants born prematurely present developmental abnormalities with greater frequency than those born at full term. ${ }^{7-9}$ Preterms may suffer from failure to thrive in terms of both height and weight, from motor development disorders, mental deficiencies, hearing loss, impaired vision, language difficulties, cardiovascular problems, respiratory problems, attention deficits and hyperactivity, among other problems. ${ }^{3,10}$

The protocol used for follow-up of patients who have spent time in neonatal intensive care units includes a motor development evaluation and countless tools have been used to help professionals working in the area make more precise functional assessments. ${ }^{11-13}$

The Alberta Infant Motor Scale (AIMS) is a standardized scale that was developed by Piper \& Darrah (1994). It is intended to evaluate and monitor the gross motor function of infants, by means of observation of spontaneous motor activity from birth to 18 months or until the child has learnt to walk unaided. ${ }^{14}$ The scale was created based on a normative sample comprising a cohort of 2,202 infants, representative of all of the children born in Alberta, Canada, between March of 1990 and June of $1992 .{ }^{14}$ It was developed to assess infants at risk of developing neuromotor dysfunctions, as a result of prematurity, low birth weight or bronchopulmonary dysplasia, among other causes. ${ }^{15}$ This is an easily-applied observational scale which involves little cost and does not demand excessive handling of the child. It should be administered by professionals in child healthcare who have knowledge of normal infant motor development and experience administering the instrument. It quantifies gross motor activity in a global score, taking into consideration three criteria related to the quality of movement: weight distribution, posture and movement against the force of gravity. ${ }^{14}$

Both the validity and reliability of the AIMS have been tested, through a careful analysis of data collected from 506 infants, in Edmonton, which is a province of Alberta, Canada, ${ }^{14}$ The results demonstrate that the AIMS is a valid and reliable instrument for evaluating the motor development of Canadian infants. ${ }^{15,16}$

The concurrent validity of the AIMS has been verified, comparing its global score with the overall scores of the motor scale from the Bayley Scales of Infant Development (BSID) and of the Peabody Development Motor Scales (PDMS). This demonstrated a high degree of congruence between the AIMS scores and those of the BSID motor scale $(r=0.97)$, and also between the AIMS scores and those from the PDMS ( $r=$ 0.99). ${ }^{14}$ The predictive capacity of the AIMS varies depending on the age at which the evaluation is made, ${ }^{17}$ and percentiles below 10 at 4 months of age and below five at 8 months of age can be considered valid and reliable indicators of motor development delay or abnormality. ${ }^{17}$

The AIMS has been used in several different studies in Brazil, $^{18}$ and is considered useful and practical for evaluation of the motor development of premature infants within follow-up programs run by the Brazilian public health system. However, it still remains necessary to verify its psychometric properties, since satisfactory levels of instrument validity and reliability are not guaranteed when instruments are used with populations that are culturally distinct from those with which they were developed. ${ }^{19,20}$ Thus, whenever a scale is to be used in a new context or with a different group of people, it will be necessary to redefine its psychometric properties.

The objective of this study is to verify the concurrent validity and interobserver reliability of the AIMS with premature infants followed up at an outpatients clinic on the Brazilian public health system (IFF/Fiocruz).

\section{Methods}

\section{Participants}

This was a cross-sectional study of a prospective cohort from the follow-up clinic at the neonatology department of the Instituto Fernandes Figueira (IFF/Fiocruz); a sample of convenience of 88 premature infants born between February of 2006 and November of 2006. The inclusion criterion was prematurity (gestational age $<37$ weeks), while infants were excluded if they had genetic syndromes, congenital malformations or congenital infections.

For the concurrent validity study, a sample was selected of 46 premature infants with birth weights less than $1,500 \mathrm{~g}$, who had been referred for evaluation with the Bayley Scales of Infant Development - 2nd ed. (BSID-II) at 6 or 12 months' corrected age. In order to detect a hypothesis of Pearson's correlation coefficient greater than 0.6 , working to a 0.05 significance level and with a power of $80 \%, 20$ children would be needed in each group. According to the same parameters, 12 infants in each group would be needed for the interobserver reliability study. A total of 42 premature infants were allocated into four age groups: 0-3, 4-7, 8-11 and 12-18 months' corrected age.

This study was submitted to and approved by the Human Research Ethics Committee at IFF/Fiocruz. The parents and guardians of all participants were given and signed informed consent forms.

\section{Instruments and procedures}

Concurrent validity is a type of criterion validity which relates the instrument under scrutiny to some other measure of the same construct, and which is ideally the closest to the "gold standard." In general, the two scales are administered at the same time by independent observers, and the results are compared. Concurrent validity is used when one wishes to substitute one instrument for another that is simpler, cheaper or less invasive. ${ }^{19}$ For this study of the concurrent validity of the AIMS, the BSID-II motor scale was defined as the gold standard. ${ }^{21}$ 
The AIMS is a scale that evaluates the gross motor development of an infant, by means of 58 items divided into four subscales: prone ( 21 items), supine ( 9 items), sitting (12 items) and standing (16 items). The evaluator observes the infant's motor performance and contributes one point for each item that is observed and zero points for each item that not observed. The total score is given by the sum of all of the points observed plus points prior to the first item observed in the development stage in which the infant is, for each subscale. Total score and corrected age then determine the infant's position on one of the percentile curves, derived from the Canadian normative population. ${ }^{14}$

The BSID-II evaluates the progressive functional development of children from 1 to 42 months of age. It has been standardized and widely recognized in the literature and was based on a normative sample comprising 1,700 children representative of the entire population of the United States. Its psychometric properties are described in the manual. ${ }^{21}$ It is divided into three scales: motor, mental and behavioral. The BSID-II scores children's performance according to their age in months, and for each month there is a specific group of items to be observed. The motor scale consists of 111 items that assess fine and gross motor development. The overall score is given by summing all of the items for which a child is given credit, within the group of items specific to their age, added to the sum of the items from earlier months. ${ }^{21}$ This raw score is transformed into a psychomotor development index (PDI), which classifies the child's development as: significantly delayed (PDI $<70)$, moderately delayed $(70 \leq$ PDI $\leq$ $84)$, normal ( $85 \leq$ PDI $\leq 114$ ) or accelerated (PDI $\geq 115) .{ }^{21}$ The BSID-II has not gone through transcultural adaptation for Brazil, but the scale is nevertheless widely used in follow-up clinics and in child healthcare research. ${ }^{22-25}$

The AIMS and the BSID-II motor scale take different approaches to evaluating development, but are designed to assess the same construct, which is motor development based on progressive evolution of motor abilities. Furthermore, both scales provide a global score which increases as child development progresses, which facilitates comparison of results. For the concurrent validity analysis, a comparison was made between the global scores of the AIMS and those of the BSID-II motor scale. The scales were administered by a physiotherapist and a psychologist, respectively, both of whom were experienced in using scales, following the study design used by the authors of the AIMS, Piper \& Darrah. ${ }^{14}$

Each examiner scored the infants' motor performance according to the scale they were using, independently and blind to each other. Infants' gross motor performance was observed by both observers at the same time, while fine motor abilities were only assessed by the psychologist, who was using the BSID-II. Gross motor ability was evaluated by both scales simultaneously in order to avoid any effect from infants behaving differently or other sources of variation that could result if evaluations were to have been carried out at different points in time, which could have had a negative influence on the results.

Two healthcare professionals took part in the interobserver reliability study (one a physiotherapist -evaluator I, and one a neurologist and physiatrist - evaluator II), both with 7 years' experience in infant motor development follow-up, and trained to administer the AIMS. Both evaluators assessed each of the infants at the same time, independently and blinded to each other. Evaluator I conducted the individual tests, while evaluator II observed and scored the infants' performance according to the AIMS. After the examination, evaluator I scored the infants' performance according to the AIMS without knowledge of evaluator II's results.

\section{Statistical analysis}

The data collected from the medical records and the results of the AIMS and BSID-II evaluations were stored on a Microsoft Excel database. Statistical analysis was carried out with the aid of the Statistical Package for Social Science for Windows (SPSS), version 10.0. Categorical variables were described in the form of proportions. Means and standard deviations were calculated for the continuous variables: corrected age (CA), gestational age (GA), birth weight (BW) and length of hospital stay (HS).

The correlation between the global AIMS and BSID-II scores was analyzed statistically using Pearson's correlation coefficient $(r)$, which is an estimate of the correlation that quantifies the degree of linear relationship between the scores, and by the determination coefficient $\left(r^{2}\right)$, which is the proportion of the variation in one measure that can be predicted by knowing the variation of the other measure. The closer to -1 or 1 that Pearson's correlation coefficient approaches, the better the linear correlation between the variables. ${ }^{19,26}$ Student's $t$ test was used to evaluate $r \neq 0$ and the significance level was set at $p<0.05$.

Interobserver reliability was determined using the intraclass correlation coefficient (ICC), which employs analysis of variance to measure the variability introduced by different observers, ${ }^{26}$ where values between 0 and 0.25 indicate little or no correlation, 0.25 to 0.50 normal correlation, 0.50 to 0.75 moderate to good correlation and values above 0.75 indicate a very good to excellent correlation. ${ }^{26}$

\section{Results}

The characteristics of the sample populations for the validity and reliability tests are given in Tables 1 and 2, respectively.

\section{Concurrent validity}

The means and their respective standard deviations (SD) for the scores for the whole population ( $n=46$ ), according to the AIMS and the BSID-II motor scale, were 35.89 (SD = $15.79)$ and $47(S D=12.81)$ respectively. The mean AIMS 
Table 1 - Characteristics of the population of infants born prematurely, followed-up at the IFF clinic and enrolled on the study of the concurrent validity of the AIMS against the BSID-II motor scale

\begin{tabular}{lccc}
\hline Characteristics & $\mathbf{6}$ months & $\mathbf{1 2}$ months & Total \\
\hline Study population & 26 & 20 & 46 \\
Corrected age (months)* & $6.5(1)$ & $12.5(1.5)$ & $25(54)$ \\
Sex & & & $28(5)$ \\
$\quad$ Male (\%) & $12(46)$ & $13(65)$ & $29(6)$ \\
Gestational age (weeks)* & $28(5)$ & $1,140.5(257.77)$ & $21(46)$ \\
Birth weight (grams)* & $1,038.8(218.36)$ & $11(55)$ & $59.8(21.5)$ \\
Small for gestational age (\%) & $10(38)$ & $56.25(23.76)$ & $34(74)$ \\
Length of hospital stay (days)* & $62.58(19.71)$ & $11(55)$ & $23(50)$ \\
Hyaline membrane disease (\%) & $23(88)$ & $7(35)$ & $15(33)$ \\
Mechanical ventilation (\%) & $16(61)$ & $6(30)$ & \\
Bronchopulmonary dysplasia (\%) & $9(35)$ & & \\
\hline
\end{tabular}

* The data above are expressed in the form of means (standard deviation).

Table 2 - Characteristics of the population of infants born prematurely, followed up at the IFF clinic and enrolled on the study of the interobserver reliability of the AIMS

\begin{tabular}{|c|c|c|c|c|c|}
\hline Characteristics & 0-3 months & 4-7 months & 8-11 months & 12-18 months & Total \\
\hline Study population & 12 & 10 & 8 & 12 & 42 \\
\hline \multicolumn{6}{|l|}{ Sex } \\
\hline Male $(\%)$ & $6(50)$ & $3(30)$ & $5(62.5)$ & $5(42)$ & $19(45)$ \\
\hline Corrected age (months)* & $2.5(1)$ & $6(1)$ & $10(1)$ & $14.5(2)$ & $8(5)$ \\
\hline Gestational age (weeks)* & $34(2)$ & $31(4)$ & $31(3)$ & $32(2)$ & $32(1)$ \\
\hline Birth weight (grams)* & $1,904(489)$ & $1,515(683)$ & $1,151(573)$ & $1,319(407)$ & $1,472(324)$ \\
\hline
\end{tabular}

* The data above are expressed in the form of means (standard deviation).

score for the 6-month-old infants $(\mathrm{n}=26)$, was 24.5 (SD = 8.2 ) and by the BSID-II it was $37.2($ SD = 5). For the 12 -month-old infants $(\mathrm{n}=20)$, the mean AIMS score was $50.75(\mathrm{SD}=9.5)$ and the mean BSID-II score was $59.8(\mathrm{SD}=$ 7.2).

Pearson's correlation coefficient for the results of the two scales was $r=0.95(p<0.01)$ for the entire sample, which is classed as excellent. The coefficient of determination $\left(r^{2}\right)$ was 0.90 , indicating that $90 \%$ of the variance in the BSID-II scores is explained by the linear relationship between the AIMS and the BSID-II. At 6 months of age, this correlation was $r=0.74$ $(p<0.01)$, which is considered from moderate to good, and $r^{2}$ was 0.55 , indicating that $55 \%$ of the variance in the BSID-II scores is explained by the linear relationship between the AIMS and the BSID-II. At 12 months of age, the correlation was $r=0.89(p<0.01)$, i.e., very good, and $r^{2}$ was 0.79 , indicating that $79 \%$ of the variance in the BSID-II scores is explained by the linear relationship between the AIMS and the
BSID-II. The linear relationship between the global scores from the AIMS and the BSID-II for the entire population can be observed in the scatter plot in Figure 1.

\section{Interobserver reliability}

Table 3 lists the means and standard deviations (SD) for the global AIMS scores awarded by evaluators I and II for the whole population and for the four age groups, broken down by subscale, in addition to the ICCs for these scores and their confidence intervals.

Interobserver reliability for the entire sample was excellent (ICC $=0.99$ ) and was also excellent for all age groups, where all ICCs were above 0.94 , with the exception of three subscale scores: standing at 0-3 months $($ ICC $=0.76)$ and at 4-7 months (ICC $=0.86$ ) and sitting at $12-18$ months (ICC $=$ $0.78)$.

\section{Discussion}

The results of the concurrent validity study demonstrated an excellent correlation between the total AIMS and BSID-II 


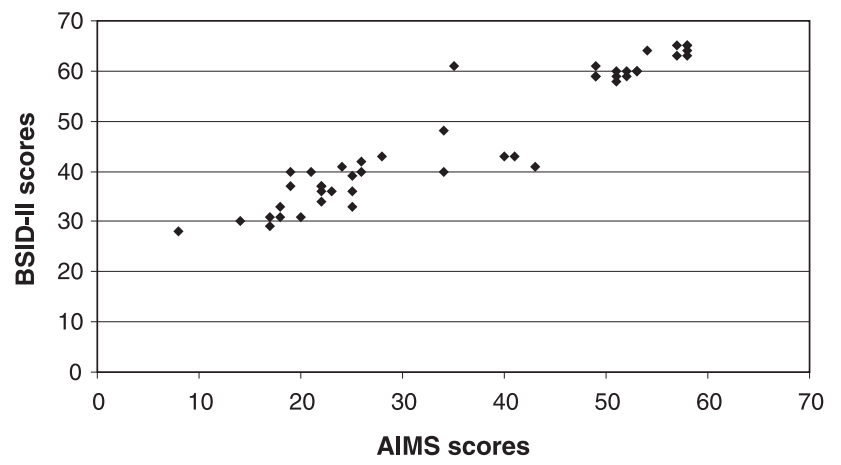

Figure 1 - Scatter plot of Alberta Infant Motor Scale (AIMS) and Bayley Scales of Infant Development - 2nd ed. (BSID-II) scores for premature infants at 6 and 12 months

motor scale scores for the population studied. The authors of the AIMS ${ }^{14}$ verified its concurrent validity comparing total AIMS scores with total BSID motor scores for a sample of 120 infants and found a correlation of $r=0.97$, which is mildly superior to the result we observed in this study, and which may be the result of the different techniques employed. While Piper \& Darrah ${ }^{14}$ used the same evaluator to apply both scales, we used two different evaluators, one for each scale. Furthermore, the study described in the AIMS manual used the first version of the BSID. ${ }^{14}$

The correlation found at 6 months was smaller than the correlation at 12 months' corrected age. These results are similar to those of Jeng et al., ${ }^{27}$ who found a concurrent validity between the total scores for the AIMS and the BSID-II motor scale, at 6 and 12 months' corrected age of a population of 41 premature Thai infants. The correlation they found was $r=0.78$ at 6 months and $r=0.90$ at 12 months' corrected age. ${ }^{27}$

It is possible that the differences between Pearson's correlation coefficient for 6 and for 12 months' corrected age is due to the differences in the processes used to score the AIMS and BSID-II scales. At 6 months BSID-II has 20 test items, with eight dedicated to fine motor abilities, whereas the AIMS only assesses gross motor abilities. It is also important to point out that at 6 months the BSID-II does not include any items to be observed in the prone position, whereas the AIMS has more items assessed in this position than in any other, at the same age.

At 12 months of age, the BSID-II has 14 test items, with three dedicated to fine motor abilities. The presence of a greater number of items on gross motor abilities may have been what increased the correlation between the AIMS and the BSID-II at this age.

The correlation found in this validity study was satisfactory and comparable with results in the literature. ${ }^{14,27}$ Very high or very low correlations were not to be expected, because the AIMS and BSID-II motor scale evaluate the same construct and motor development, but use different methodological approaches to do so.

A Brazilian study has demonstrated a good level of agreement between results obtained using the AIMS and the BSID-II with infants born at full term when they reached 6 months of age. That study suggests that the AIMS can be used as an alternative method for screening for abnormal motor development in infants at early ages. ${ }^{28}$

Despite the satisfactory results of this and other studies that have taken the BSID-II as the gold standard, we should not rely on this as the only method of verifying the validity of the AIMS, since there is no confirmation in the literature that there is any good measurement criterion or adequate gold standard. Some studies of the concurrent validity between the BSID-II and other scales that have been based on normative samples and are recognized in the literature have found little concordance. $21,29,30$

In the interobserver reliability study, the correlation found between the results of evaluator I and those of evaluator II, for the overall population, were excellent. The result found in this study was the same as the result for interobserver reliability (correlation of 0.99 ) found by Piper et al. ${ }^{15}$ This indicates that the AIMS is a reliable instrument for use with the premature infants at the IFF/Fiocruz clinic, once the health professionals there have been trained to apply the scale.

The correlations between the two professionals were also evaluated for each subscale of the AIMS and for each age group. The intraclass correlation coefficients for each of the four subscales separately, demonstrated an excellent correlation for the whole sample. When broken down by the four age groups, the results also demonstrated an excellent correlation between evaluators for the total AIMS scores.

The standing subscale exhibited the lowest reliability in terms of ICC, in the 0-3 months (ICC $=0.76$ ) and 4-7 months $($ ICC $=0.86)$ age groups. This lower degree of correlation observed for the standing subscale, between 0 and 7 months of age, may be the result of the small number of items (just three) that infants are able to perform before the age of 8 months.

These results are similar to those published by Jeng et al. ${ }^{27}$ The lowest ICC found by those authors (ICC $=0.73$ ) was on the standing subscale for a group of premature infants at 0 to 3 months' corrected age $(n=15)$.

For the group of infants aged 12-18 months, the lowest correlation found was in the sitting subscale (ICC $=0.78$ ). The fact that this subscale coefficient is lower than the others for the same age group may be because infants predominantly move themselves in a standing position at this age, and it is difficult to observe their performance while sitting.

The AIMS' ease of application, low cost and satisfactory values for validity and reliability, as demonstrated in this 
Table 3 - Results of the interobserver reliability study

\begin{tabular}{|c|c|c|c|}
\hline & Evaluator I* & Evaluator II* & ICC (CI) \\
\hline \multicolumn{4}{|c|}{ Total sample $(n=42)$} \\
\hline Global score & $32.83(19.65)$ & $32.69(19.64)$ & $0.99(0.99-1.00)$ \\
\hline Prone & $12.05(8.03)$ & $12.02(8.03)$ & $0.99(0.99-1.00)$ \\
\hline Supine & $6.76(2.68)$ & $6.71(2.78)$ & $0.98(0.98-0.99)$ \\
\hline Sitting & $7.40(4.56)$ & $7.38(4.50)$ & $0.99(0.99-1.00)$ \\
\hline Standing & $6.62(5.32)$ & $6.57(5.32)$ & $0.99(0.99-1.00)$ \\
\hline \multicolumn{4}{|c|}{$0-3$ months $(n=12)$} \\
\hline Global score & $10.60(4.10)$ & $10.60(4.10)$ & $0.99(0.99-1.00)$ \\
\hline Prone & $3.40(2.20)$ & $3.40(2.20)$ & $0.96(0.89-0.99)$ \\
\hline Supine & $3.40(1.70)$ & $3.25(1.60)$ & $0.94(0.81-0.98)$ \\
\hline Sitting & $1.83(0.94)$ & $1.90(0.90)$ & $0.95(0.84-0.98)$ \\
\hline Standing & $1.90(0.70)$ & $1.92(0.51)$ & $0.76(0.38-0.92)$ \\
\hline \multicolumn{4}{|c|}{ 4-7 months $(n=10)$} \\
\hline Global score & $23.00(5.70)$ & $22.50(9.55)$ & $0.99(0.98-1.00)$ \\
\hline Prone & $7.60(4.74)$ & $7.80(4.52)$ & $0.99(0.96-0.99)$ \\
\hline Supine & $6.60(2.00)$ & $6.50(2.17)$ & $0.99(0.96-1.00)$ \\
\hline Sitting & $5.90(3.03)$ & $5.80(3.00)$ & $0.98(0.94-0.99)$ \\
\hline Standing & $2.60(0.80)$ & $2.60(0.80)$ & $0.86(0.55-0.96)$ \\
\hline \multicolumn{4}{|c|}{ 8-11 months $(n=8)$} \\
\hline Global score & $48.00(7.31)$ & $48.00(7.13)$ & $0.99(0.97-1.00)$ \\
\hline Prone & $19.13(2.95)$ & $19.00(2.88)$ & $0.99(0.97-0.99)$ \\
\hline Supine & $8.87(0.35)$ & $9.00(0.00)$ & $1.00(1.00-1.00)$ \\
\hline Sitting & $11.13(1.73)$ & $11.13(1.73)$ & $1.00(1.00-1.00)$ \\
\hline Standing & $8.88(2.75)$ & $8.88(3.00)$ & $0.98(0.93-0.99)$ \\
\hline \multicolumn{4}{|c|}{$12-18$ months $(n=12)$} \\
\hline Global score & $53.42(6.89)$ & $53.17(7.38)$ & $0.99(0.98-1.00)$ \\
\hline Prone & $19.67(3.55)$ & $19.66(3.77)$ & $0.99(0.98-1.00)$ \\
\hline Supine & $8.83(0.58)$ & $8.83(0.57)$ & $1.00(1.00-1.00)$ \\
\hline Sitting & $11.75(0.87)$ & $11.67(0.65)$ & $0.78(0.43-0.93)$ \\
\hline Standing & $13.17(3.21)$ & $13.00(3.44)$ & $0.98(0.95-0.99)$ \\
\hline
\end{tabular}

CI = confidence interval; ICC $=$ intraclass correlation coefficient.

* The scores awarded by evaluators I and II are given as means (standard deviation).

study, make it an instrument of great utility within the Brazilian public health system, both for following-up the motor development of premature infants during their first year of life and for use in research.

\section{References}

1. Ministério da Saúde. Indicadores e dados básicos [série on-line]. Brasil. 2005. http://tabnet.datasus.gov.br. Access: 20/12/ 2006.
2. de Carvalho M, Gomes MA. A mortalidade do prematuro extremo em nosso meio: realidade e desafios. J Pediatr (Rio J). 2005;81: S111-8.

3. Hack M. Young adult outcomes of very-low-birth-weight children. Semin Fetal Neonatal Medi. 2006;11:127-37.

4. Procianoy RS, Guinsburg R. Avanços no manejo do recém-nascido prematuro extremo. J Pediatr (Rio J). 2005;81: S1-2.

5. Taylor HG, Klein N, Drotar D, Schluchter M, Hack M. Consequences and risks of $<1000-\mathrm{g}$ birth weight for neuropsychological skills, achievement, and adaptive functioning. J Dev Behav Pediatr. 2006;27:459-69. 
6. Wilson-Costello D, Friedman H, Minich N, Fanaroff AA, Hack M. Improved survival rates with increased neurodevelopmental disability for extremely low birth weight infants in the 1990s. Pediatrics. 2005;115:997-1003.

7. Marlow N, Wolke D, Bracewell MA, Samara M; Epicure Study Group. Neurologic and developmental disability at six years of age after extremely preterm birth. N Engl J Med. 2005;352: 9-19.

8. Silveira RC, Procianoy RS. Lesões isquêmicas cerebrais no recém-nascido pré-termo de muito baixo peso. J Pediatr (Rio J). 2005;81:S23-32.

9. Rugolo LM. Crescimento e desenvolvimento a longo prazo do prematuro extremo. J Pediatr (Rio J). 2005;81:S101-10.

10. de Mello RR, Dutra MV, Ramos JR, Daltro P, Boechat M, Lopes JM. Neonatal risk factors for respiratory morbidity during the first year of life among premature infants. Sao Paulo Med J. 2006;124:77-84.

11. Edwards SL, Sarwark JF. Infant and child motor development. Clinical Clin Orthop Relat Res. 2005;(434):33-9

12. Harris SR, Heriza CB. Measuring infant movement. Clinical and technological assessment techniques. Phys Ther. 1987;67: 1877-80.

13. Rosenbaum P. Screening tests and standardized assessment used to identify and characterize developmental delays. Semin Pediatr Neurol. 1998;5:27-32.

14. Piper MC, Darrah J, editors. Motor assessment of the developing infant. Alberta: Saunders; 1994.

15. Piper MC, Pinnell LE, Darrah J, Maguire T, Byrne PJ. Construction and validation of the Alberta Infant Motor Scale (AIMS). Can J Public Health. 1991;83 Suppl 2:S46-50.

16. Bartlett DJ, Fanning JE. Use of the Alberta Infant Motor Scale to characterize the motor development of infants born preterm at eight months corrected age. Phys Occup Ther Pediatr. 2003;23: 31-45.

17. Darrah J, Piper M, Watt MJ. Assessment of gross motor skills of at-risk infants: predictive validity of the Alberta Infant Motor Scale. Dev Med Child Neurol. 1998;40:485-91.

18. Manacero S, Nunes ML. Evaluation of motor performance of preterm newborns during the first months of life using the Alberta Infant Motor Scale (AIMS). J Pediatr (Rio J). 2008;84:53-9.

19. Streiner DL, Norman GR. Health measurement scales: a practical guide to their development and use. Oxford: Oxford University Press; 1995.
20. Behling O, Law KS. Translating questionnaries and other research instruments. problems and solutions. Thousand Oaks, CA: Sage; 2000.

21. Bayley N. Bayley Scales of Infant Development. 2nd ed. San Antonio, TX: The Psychological Corp; 1993.

22. Andrade SA, Santos DN, Bastos AC, Pedromônico MR, de Almeida-Filho $\mathrm{N}$, Barreto $\mathrm{ML}$. Ambiente familiar e desenvolvimento cognitivo infantil: uma abordagem epidemiológica. Rev Saúde Pública. 2005;39:606-11.

23. Goto MM, Gonçalves VM, Netto AA, Morcillo AM, Moura-Ribeiro MV. Neurodesenvolvimento de lactentes nascidos a termo pequenos para a idade gestacional no segundo mês de vida. Arq Neuropsiquiatr. 2005;63:75-82.

24. Mello BB, Gonçalves VM, Souza EA. Comportamento de lactentes nascidos a termo pequenos para a idade gestacional no primeiro trimestre de vida. Arq Neuropsiquiatr. 2004;62:1046-51.

25. Mello RR, Dutra MV, Silva KS, Lopes JM. Valores de predição da avaliação neurológica e ultra-sonográfica cerebral neonatal em relação ao desenvolvimento de prematuros de muito baixo peso. Rev Saúde Pública. 1998;32:420-9.

26. Fleiss J L. Statistical methods for rates and proportions. New York: John Wiley \& Sons; 1981.

27. Jeng SF, Yau KI, Chen LC, Hsiao SF. Alberta Infant Motor Scale: reliability and validity when used on preterm infants in Taiwan. Phys Ther. 2000;80:168-78.

28. Campos D, Santos DC, Gonçalves VM, Goto MM, Arias AV, Brianeze AC, et al. Agreement between scales for screening and diagnosis of motor development at 6 months. J Pediatr (Rio J). 2006;82:470-4.

29. Provost B, Crowe TK, McClain C. Concurrent validity of de Bayley Scales of Infant Development II Motor Scale and the Peabody Developmental Motor Scales in two-year-old children. Phys Occup Ther Pediatr. 2000;20:5-18.

30. Connolly BH, Dalton L, Smith JB, Lamberth NG, McCay B, Murphy W. Concurrent validity of the Bayley Scales of Infant Development II (BSID-II) Motor Scale and the Peabody Developmental Motor Scale II (PDMS-2) in 12-month-old infants. Pediatr Phys Ther. $2006 ; 18: 190-6$.

Correspondence:

Kênnea Martins Almeida

Rua Quintino Bocaiúva, 247/402

CEP 36015-010 - Juiz de Fora, MG - Brazil

E-mail: kenneajf@superig.com.br,kenneajf@ig.com.br 